\title{
Lazer, esporte e cultura na agenda local: a experiência de promoção da saúde em Manguinhos
}

\author{
Leisure, sports and culture on the local agenda: \\ the $\mathrm{M}$ anguinhos' health promotion experience
}

Fabio de Faria Peres 1

Regina Bodstein 1

Célia Leitão Ramos 1

Willer Baumgarten Marcondes 1

\footnotetext{
1 Departamento de Ciências Sociais. Escola Nacional de Saúde Pública Sérgio Arouca. Rua Leopoldo Bulhões 1.480 , sala 915 .

M anguinhos, 21041-210, Rio de Janeiro RJ. peres@ensp.fiocruz.br
}

Abstract Located in the north zone of Rio de Janeiro City and consisting of eleven slums, M anguinhos is marked by poverty and social inequalities, showing a lack of public policies. The constitution of a Local Development (DL) and $\mathrm{H}$ ealth Promotion policy in the region revitalized the association life and raised a heated debate about the present demands. The main focus is to understand the meanings and values that the community leaders attribute to leisure, sport and culture and the political practice and relation between these leaderships, and their internal conflicts. Differences in the everyday political practice of the community leaders were identified. This creates a scenario permeated by cleavages and political distrust which represent "collective action dilemmas". Consequently, one of the conclusions indicates little ability for cooperative action between the different local leaderships, which as a result impairs the development of a common agenda to be negotiated with the public sector or other local social organizations and makes it difficult to put forward the demands, particularly those concerning leisure, culture and sport. Additionally, we concluded that initiatives in these subject are very important to $M$ anguinhos' communities. Key words Leisure, Health promotion, Local agenda, Community initiatives
Resumo Localizada na Zona N orte da cidade do Rio de Janeiro e composta por 11 favelas, a re gião de $M$ anguinhos é marcada pela pobreza e pela desigualdade, demonstrando o estado de omissão de políticas públicas. Constituiu-se naquela região uma política de Desenvolvimento Local (DL) e de Promoção da Saúde que provocou uma revitalização da vida associativa e um intenso debate acerca das demandas presentes nas comunidades. Lazer, cultura e esporte apareceram como forte demanda das lideranças comunitárias. Este artigo trata da compreensão dos significados e valores que os líderes comunitários atribuem ao lazer, à cultura e ao esporte. Buscamos entender a prática e a ação dessas lideranças e seus conflitos internos no papel de mediadores culturais. Foram identificadas diferenças na prática política entre os líderes comunitários. Tratase de um cenário permeado por clivagens e desconfianças que representam consideráveis "dilemas da ação coletiva". Assim, a baixa capacidade de ação cooperativa entre as diversas lideranças locais acaba por prejudicar a elaboração de uma agenda comum a ser negociada com o poder público e demais organizações sociais do local, dificultando o encaminhamento das demandas, em particular, aquelas em torno de lazer, esporte e cultura.

Palavras-chave Lazer, Promoção da saúde, Agenda local, Iniciativas comunitárias 
Pode-se dizer que a liberdade de articular e perseguir demandas por reconhecimento éa principal condição de autonomia, da capacidade prática de autoconstituição (e, portanto, potencialmente, de auto - avanço) da sociedade em que vivemos [...] (Bauman, 2003).

\section{Introdução}

Experiências e projetos sociais de lazer, esporte e cultura são cada vez mais presentes no Rio de Janeiro, sobretudo, voltados para crianças e jovens moradores de favela. Secretarias públicas, organizações não-governamentais e empresas privadas elaboram, financiam e implementam, com grande visibilidade, projetos desse cunho. Essas iniciativas revelam o espaço que a questão vem ocupando na agenda pública voltada para as populações residentes em comunidades carentes da cidade, deixando entrever a existência de uma demanda crescente por projetos e iniciativas sociais desse tipo.

O campo da Promoção da Saúde voltado para iniciativas comunitárias e programas de saúde reconhece que melhorias nas condições de saúde e na qualidade de vida pressupõem uma visão integradora das políticas sociais, onde o diálogo interdisciplinar, as ações intersetoriais e a participação das comunidades envolvidas adquirem centralidade (Potvin et al., 2001; Rootman et al., 2001). Nessa perspectiva, políticas e programas de promoção da saúde mais inovadores preocupam-se com os determinantes econômicos, sociais, culturais, ambientais e políticos vocalizados pelas próprias comunidades dentro de contextos de pobreza e exclusão social. Abordagens avaliativas em torno de um conjunto amplo de experiências de promoção da saúde têm mostrado a importância crescente das iniciativas educacionais, de cultura e lazer, quando a meta são mudanças locais efetivas e sustentáveis. A literatura atual sobre avaliação em promoção da saúde enfatiza que a efetividade dos programas e das iniciativas de melhoria da saúde e da qualidade de vida implicam um profundo envolvimento dos atores e da população beneficiária. Esse envolvimento será mais efetivo na medida em que considera o processo de (re) construção de identidades culturais, fortalecimento da cidadania ativa e das redes sociais locais (Pawson, 2003; Sullivan \& M atka, 2002).

A identificação e a valorização do circuito local de sociabilidade e dos padrões e ativida- des sócio-recreativas e culturais prevalecentes nas comunidades - como indicador da maior ou menor presença do chamado capital social (Putnam, 2000) constituem um passo fundamental para a mobilização e participação das comunidades nos programas de promoção da saúde, mesmo em situações de grande privação material, exclusão social e ausência de equipamentos urbanos básicos. $\mathrm{Na}$ literatura internacional a temática sobre promoção da saúde aparece tanto vinculada a uma esfera individual, na medida em que relaciona o estilo de vida com o risco de contrair doenças - por exemplo as campanhas que estimulam a prática de atividades físicas, a alimentação saudável, entre outras medidas -, quanto a um processo coletivo ou comunitário em sua dimensão sociocultural, e, portanto, como política pública. N este sentido, lazer e cultura tanto podem influenciar o processo saúde/doença - quer no plano individual ou no coletivo - como também as políticas públicas a partir de uma perspectiva integrada e intersetorial de desenvolvimento e de melhoria da qualidade de vida. A perspectiva deste artigo relaciona lazer e cultura com a presença dos chamados mediadores culturais que atuam como lideranças comunitárias, propiciando um contexto favorável de discussão e interação em torno das iniciativas de promoção da saúde e de desenvolvimento local. É, portanto, do lazer e da cultura como demanda social, política pública e dimensão importante dos projetos de melhoria da qualidade de vida e da saúde que trata este artigo.

N ossa indagação diz respeito à importância que as iniciativas no campo da cultura e do lazer ocupam no imaginário e nas demandas das comunidades carentes e faveladas da cidade do Rio de Janeiro, e em M anguinhos, em particular, comunidade vizinha da Fiocruz e envolvida em uma diversidade de iniciativas de promoção da saúde e de desenvolvimento local (Buss, 2000; Zancan, et al.,2002). Assim, nossa preocupação é compreender significados e valores que as lideranças comunitárias de $\mathrm{M}$ anguinhos atribuem ao lazer e às iniciativas nesse campo, entendendo que tais lideranças desempenham uma função central de mediação cultural.

O ponto de partida foi a real ização de um extenso trabal ho de campo em torno de um diagnóstico participativo, da constituição de uma agenda e de fóruns de discussão de desenvolvimento local em $M$ anguinhos. Esse processo evidenciou que reivindicações pelo acesso 
aos bens culturais e a equi pamentos específicos de lazer apareciam se não como absoluta prioridade diante da precariedade de infra-estrutura urbana, pelo menos como uma demanda consensual e urgente entre as lideranças e principais representantes da região (FCDDHBR, 2000; Bodstein et al., 2001; Peres, 2004).

\section{Aspectos conceituais}

D ebates recentes acerca das possibilidades de acesso ao lazer deixam entrever as diversas representações e valores atribuídos ao termo, resultando em entendimentos diferenciados e às vezes divergentes. 0 próprio uso indiscriminado da palavra "Iazer" suscita significados - por vezes contraditórios - que se reduzem apenas às suas manifestações e aos conteúdos da ação, como: "jogar bola", "distração", "prazer", "ir ao teatro", "descanso", "ver um filme", entre outros. Por outro lado, observa-se uma visão tradicional, em que o lazer é pensado exclusivamente em oposição ao trabalho. Concebido como tempo totalmente alienado e alienante, contraditoriamente aparece também representado como tempo da absoluta liberdade e motor de profundas mudanças sociais ( $M$ asi, 2000). Além disso, a temática do lazer e da cultura, aparentemente, concorre, em contextos de grande desigualdade e de exclusão social, com outras temáticas e necessidades vistas como mais importantes e básicas para a qualidade de vida. Assim, o direito ao lazer e à cultura freqüentemente aparece como um aspecto secundário, se não de viés elitista.

O lazer, sem dúvida, ocorre num tempo específico caracterizado pela ausência de um certo gênero de obrigações e deveres profissionais, familiares, religiosos, entre outros. Conseqüentemente, é caracterizado como o espaço do lúdico e prazeroso vinculado à satisfação pessoal sem fins funcionais e utilitários, expressando a cultura de um grupo ou sociedade (M elo \& Alves, 2003; Dumazedier, 1999; 2001). 0 termo cultura aqui empregado não se limita apenas aos seus equipamentos, às suas manifestações, nem tampouco ao que tradicionalmente é considerado de "alta cultura", "culto", de "bom gosto" ou exclusivamente às manifestações artísticas. Ao invés de ser concebida somente como produto, entendemos a cultura de uma forma ampliada e plural, isto é, além da arte, do "erudito", refere-se ao cotidiano, ao pensado, aos valores, ao simbólico entre tantos outros aspec- tos da vida social (Brant, 2002; Faria, 2003; Kliksberg \& Tomassini, 2000).

Desta forma, as atividades de lazer são atividades culturais em seu sentido amplo, que se distinguem pela conjunção sui generis entre tempo (disponível) e propensão (busca pelo prazer/satisfação). Ao ser tomado como uma forma de expressão cultural, o lazer, se por um lado pode ser visto como mecanismo dehomogeneização ou difusor/reprodutor do status quo, apresenta, ao mesmo tempo, o potencial de suscitar e expressar diversas formas de sociabilidade e de reciprocidade, dado seu caráter relacional, educativo e crítico-reflexivo. Ao nos referirmos a uma política de lazer estamos fundamentalmente falando de uma intervenção no âmbito da cultura. Logo, a política de lazer deve ser compreendida como política cultural, assumindo a relação existente entre lazer e cultura, que apesar de não serem dimensões totalmente coincidentes, são, sem dúvida, campos com inúmeros pontos de contato (Aguileta, 2000).

Por outro lado, ao serem confundidos exclusivamente com as suas manifestações, esses campos - lazer e cultura - dificilmente são considerados a partir dos determinantes e das condições socioculturais prevalecentes nas chamadas sociedades modernas (Giddens, 2002). Como nos diz Anthony Giddens, uma das características básicas das sociedades contemporâneas é o enfraquecimento dos laços preestabelecidos com outros indivíduos e grupos. Laços de parentesco de vários tipos que ancoravam as experiências de vida dos indivíduos na maioria dos contextos pré-modernos foram quase totalmente destruídos. São condições propícias a uma crescente individualização e fragmentação social, onde a vida surge como uma trajetória relacionada acima de tudo aos projetos e planos do indivíduo (Giddens,2002; Velho, 1999a,1999b, 2001). Individualidade e impessoalidade, multiplicidade dos contatos e pluralidade de circuitos aparecem como características gerais que moldam comportamentos e experiências, exigindo novas habilidades, papéis e identidades de acordo com os diferentes estilos de vida e visões de mundo - conflitantes ou não. Como assinala Kuschnir (1999): Com a expansão dos círculos sociais, característica do meio urbano, o indivíduo ganha espaço para uma mobilidade real e simbólica, para além de um único grupo de pertencimento (Simmel, 1939). $\mathrm{Na}$ metrópole, afrouxam-se os laços do indivíduo com os que lhe estão mais próximos, permitindo 
a criação de vínculos com círculos sociais mais amplos e diferenciados (Simmel,1987). U ma das características da metrópole é a coexistência de diferentes estilos de vida e visões de mundo - ou múltiplos planos de realidade -, que garantem ao indivíduo ao mesmo tempo 0 acesso e recorte desses domínios.

Diante da intensificação dos contatos, a pluralidade de circuitos, de identidades e de papéis, o indivíduo tem necessidade de interpretar, compreender e acionar códigos referentes a universos simbólicos diferenciados. A possibilidade de trânsito entre dimensões ou "campos" culturais passa a ser uma característica extremamente valorizada. $\mathrm{Na}$ medida em que cada vez mais [...] a construção do indivíduo e da sua subjetividade se dá através de pertencimento e participação em múltiplos mundos sociais e níveis de realidade (Velho, 2001) - , o papel de mediador é crucial, dada sua capacidade de transitar elidar com vários códigos e papéis, estabel ecen do interação e comunicação entre categorias sociais e níveis culturais distintos. A função de mediador cultural em $M$ anguinhos, como veremos, consiste justamente em apresentar e ampliar um "campo de possibilidades" associado a diversos "mundos" culturais.

\section{Contexto local e estratégia de pesquisa}

M anguinhos, bairro localizado na Zona N orte da cidade do Rio de Janeiro, é também a denominação de um complexo formado por 11 favelas, totalizando uma população de aproximadamente 40.000 habitantes. A pesar das peculiaridades - a região abriga inúmeras empresas e indústrias, sendo vizinha de uma refinaria e da Fundação O swaldo Cruz - , o caso de M anguinhos não é diferente da maioria das favelas. Local marcado pela pobreza, o Complexo explicita a precariedade ou omissão de políticas públicas e a situação de exclusão social, configurando claramente, como assinala Alba Zaluar, uma manifestação de injustiça distributiva. Isto é, uma situação em que pessoas são sistematicamente excluídas dos serviços, benesses e garantias oferecidos ou assegurados pelo Estado, pensados, em geral, como direitos de cidadania (1997).

Embora $M$ anguinhos muito se assemelhe a outras favelas em vista das dificuldades comuns, apresenta uma especificidade que merece destaque: a constituição de um programa de Desenvolvimento Local Integrado e Sustentá- vel (DLIS) que a partir de 1999 vem mobilizando diversas parcerias e lideranças locais. 0 programa se constituiu através de uma estratégia ampla e inovadora de interven ção social e de promoção da saúde, sobretudo diante do contexto tradicional de assistencialismo/clientelismo e enfraquecimento da cidadania (Bodstein \& Zancan, 2002). O DLIS partiu de uma concepção integrada de desenvolvimento (cultural, econômico, social) em que duas estratégias têm sido destacadas: a participação popular na definição das prioridades locais, através de processos participativos de diagnóstico, planejamento e avaliação; e colaboração intersetorial, através da coordenação do trabalho de diversos setores do governo e da comunidade, visando à formulação de uma agenda comum. 0 programa procurou estabelecer um processo de participação, interlocução e de pactuação entre os diversos parceiros/atores envolvidos, com o fortalecimento e ampliação das relações entre governo e sociedade civil, nas quais novos arranjos institucionais e novas formas de participação, organização e representatividade política ganharam destaque (Buss, 2000).

Vale afirmar que o principal desafio para a definição de uma agenda de desenvolvimento local traduziu-se na dificuldade de alcançar consenso sobre os principais parceiros, estraté gias e prioridades de médio e longo prazo. De fato, estas dificuldades apontaram para a existência de conflitos e uma certa clivagem de interesses e perspectivas entre as próprias lideranças comunitárias (Bodstein et al., 2004). Não obstante, a importância das atividades culturais, recreativas e esportivas como um caminho possível de fortalecimento de vínculos sociais e de maior coesão entre as comunidades que compõem o complexo de $M$ anguinhos apareceu como uma questão de relativo consenso para o conjunto das lideranças locais.

Diante deste panorama, em que medida 0 lazer se constituiria em uma demanda? Qual seria a percepção geral das lideranças comunitárias a este respeito? Em vista da precariedade de infra-estrutura urbana e da situação de exclusão social, não seria um aspecto supérfluo? Qual a reivindicação das lideranças comunitárias e suas iniciativas nesse campo? Q uais seriam as suas motivações? Q uais seriam os significados atribuídos ao lazer que o tornaria suficientemente importante a ponto de se tornar uma demanda e uma reivindicação importante? Qual seria o papel que tais líderes desempenham nesse campo? E, por fim, quais seriam os 
principais desafios políticos que estes líderes enfrentariam para reivindicar iniciativas no âmbito do lazer?

A partir dessas indagações, construímos uma estratégia metodológica dividida em dois momentos distintos. Inicialmente, em conjunto com a pesquisa Vida Associativa e Fórum Regional no Complexo de M anguinhos (Bodstein \& Zancan, 2003) - foram aplicados questionários aos representantes de organizações sociais do Complexo de M anguinhos. Foram convidados 20 líderes comunitários, sendo que 18 se dispuseram a responder ao questionário. Dentre estes, apenas um não completou todas as etapas do questionário. Tal universo fora definido previamente a partir da análise das atas do Fórum Regional e do mapeamento de entidades e iniciativas sociais de $M$ anguinhos. A discussão específica referente à cultura e ao lazer, inserida no questionário, visou, de forma exploratória, alargar a perspectiva de análise e revelar aspectos até então não identificados, bem como ratificar o fato de que a temática aparecia como a terceira prioridade entre as ações destacadas pelas lideranças para a região.

Num segundo momento, com intuito de aprofundar a análise, optou-se por uma perspectiva mais etnográfica, baseada fundamentalmente em entrevistas semi-estruturadas e na observação participante, visando a uma "descrição densa" da temática em estudo (Geertz, 1989). A intenção foi uma aproximação e exploração do universo discursivo dos atores e com a riqueza de significações e sentidos que a temática poderia adquirir em contextos sociais específicos. Assim, foram entrevistados 11 dos principais líderes ou representantes comunitários que demonstraram envolvimento - alguns de forma direta e outros indireta - com temas, propostas e iniciativas ligadas ao lazer e à cultura.

\section{"Cultura, lazer e esporte" na agenda local}

A situação de exclusão social enfrentada pelas camadas populares e população favelada está longe de anular a capacidade reflexiva e crítica, de produzir cultura, gerar conhecimento, enfim, de criar e recriar uma sociabilidade cotidiana, participando de diversas formas de associativismo e manifestações coletivas. $M$ arcos Alvito ao analisar as diversas significações atribuídas à favela ao longo da história nos dá um bom exemplo do perigo de se ter uma visão reducionista da questão: A favela, na tradição brasileira e, mais particularmente, carioca, é o lugar por excelência da desordem. É vista como enclave de selvageria em pleno coração da nossa metrópole mais chic, mais civilizada, mais up-to-date. Ao longo do século XX, foi representada como um dos fantasmas predi letos do imaginário urbano: a) foco de doenças, de mortais epidemias; b) sítio por excelência de malandros ociosos, negros malemolentes, inimigos do trabalho duro e honesto; c) amontoado promíscuo de populações sem moral; d) reduto anacrônico de migrantes de origem rural mal-adaptados às excelências da vida urbana, constituindo uma massa ignara a atrasar nosso desenvolvimento econômico e político; e) por fim, na sua mais recente e aterradora versão, covil de bandidos, zona franca do crime e do tráfico, onde quadrilhas, empunhando armas de último tipo capazes de alcançar nossas janel as de vidro, imperam sob a complacência de comunidades aplacadas por práticas assistencialistas deslocadas (2001).

0 reducionismo se manifesta na dificuldade de relativizar nossa percepção sobre as camadas populares, de compreender o "outro" ou o diferente em seus próprios termos. Dessa forma, foi necessário superar a perspectiva de uma suposta e conhecida (des) ordem nos espaços favelados, passando a perceber significados e sentidos, nas relações cotidianas, na ocupação dos espaços e nos estilos de vida. Foi tentar "ver" e perceber aquilo que à primeira vista se figura familiar, mas que possui uma complexidade intrínseca (Velho, 1999b). Enfim, foi necessário um esforço analítico de "relativizar" nosso olhar, colocando em questão as categorias e noções que fazem parte da nossa tradicional "visão de mundo". A abordagem e o estudo dos microespaços políticos e de sociabilidade diferentes permitiram, como no caso de $M$ anguinhos, 0 entendimento da complexidade das instâncias da vida associativa e das iniciativas locais que permeiam as comunidades locais. De fato, como afirma Karina Kuschnir, o interessante éjustamente investigar práticas que desafiam a lógica institucional mais ampla, mostrando o quanto esta pode ser permeável a princípios políticos os mais diversos (2000).

Como vimos, foi constatada a enorme demanda das comunidades e, portanto, a importância atribuída às atividades de esporte, cultura e lazer, evidenciando que apesar de todas as dificuldades e carências em relação ao saneamento e a infra-estrutura urbana, lazer e cultu- 
ra eram questões relevantes para os representantes dos moradores de $M$ anguinhos e demais lideranças locais. Além disso, pareceu importante aprofundar as manifestações e espaços de lazer existentes na área, tais como campos de futebol, samba, festas, carnaval, arte, bares. Aliás, como destaca Victor M elo ao se referir às favelas: [...] não cabe [...] chegar à comunidade com preconceitos e acreditando que exista uma ligação direta entre pobreza e infelicidade; nem tampouco acreditar que o processo de dominação cultural se dá de forma completa, anulando definitivamente todas as suas manifestações culturais (2003).

Buscou-se então precisar o sentido e analisar os significados que iniciativas nas áreas de esporte, cultura e lazer poderiam adquirir na percepção dos representantes locais. A grande maioria dos entrevistados, com uma única exceção, considerou fundamental para a região as políticas e as iniciativas nessas áreas. Dentre estes, pode-se visualizar dois grupos. 0 primeiro grupo, que apesar de considerar essenciais tais ações, não as consideram as de maior prioridade ou, por assim dizer, da "ordem-do-dia", tendo em vista a natureza complexa da realidade de Manguinhos. Já o outro grupo aponta as iniciativas e as políticas de cultura, lazer e esporte como demanda prioritária eemergencial. Assim, mesmo considerando estas duas percepções distintas, há entre os representantes locais a concordância de que tais iniciativas são, em maior ou menor grau, essenciais para M anguinhos.

\section{Mediação cultural em Manguinhos}

A pesquisa permitiu compreender que a ação dos representantes comunitários de $M$ anguinhos na área da "cultura, esporte e lazer" se dá através de diversas atividades, como capoeira, futebol, dança, música, teatro, cinema/vídeo, vôlei, passeios, fotografia, cursos e palestras em geral. Estas atividades são caracterizadas não apenas por conversas ligadas diretamente à atividade em si, mas a um conjunto de representações, valores, crenças, entre outros. Temas ligados à educação, saúde, disciplina, respeito, confiança e ética, fazem parte do repertório de assuntos abordados pel os líderes comunitários. Importa perceber a existência de um potencial pedagógico embutido nessas atividades, já que identidades e uma certa ordem moral pode ser reforçada ou (re)construída. As atuações envol- vem um agregado de significados e experiências vividas pelos rep resentantes comunitários que transitam por campos culturais distintos, abrangendo diversos objetivos e tecnologias pedagógicas.

As atividades desenvolvidas refletem um entendimento sobrea situação social, o contexto de violência e de falta de oportunidades educacionais e de ascensão social oferecidas às crianças e aos jovens das comunidades de $\mathrm{M}$ anguinhos. Existe na verdade um consenso entre os líderes comunitários com respeito à capacidade e à potencialidade de que iniciativas no campo do "lazer, esporte e cultura" possam atenuar ou remediar de certo modo essa situação de exclusão, na medida em que apresentam alternativas a estes jovens e crianças. Assim, apesar de as lideranças comunitárias transitarem entre diversas estratégias e modos de atuação, podemos afirmar que há uma predominância de um aspecto que podemos chamar de transformativo ou reflexivo. Diante de circunstâncias tão adversas, as atividades recreativas e culturais representam a possi bilidade de reação ou superação de certa passividade, já que alternativas transformadoras constituem o foco destas atividades. 0 consenso em relação à capacidade de reflexão sobre as circunstâncias, de apresentar e traduzir valores, informações e códigos de mundos sociais distintos, não anula as diferenças nas estratégias de atuação, ou seja, no que pode ser visto como uma mediação cultural transformadora.

Os mediadores culturais, como nos referimos anteriormente, estabelecem pontes, criando condições para que haja contatos e interações entre campos/contextos culturais distintos. 0 mediador é, assim, o cruzamento, o pólo e o ponto de convergência e comunicação cultural, que o diferencia de outros indivíduos que apenas circulam entre os "mundos" e níveis de cultura. Foi possível identificar que a função de mediador cultural constitui a principal atribuição dos representantes comunitários de $\mathrm{M}$ anguinhos, consistindo justamente na ampliação do "campo de possibilidades". De certa forma, representam um esforço para ampliar e fortalecer laços com a sociedade inclusiva, através da promoção de valores ligados à cidadania e ao combate à desigual dade social. Implícita ou explicitamente tratam de transformar trajetórias - condicionadas e limitadas pelo contexto social da pobreza e da exclusão - através de iniciativas que ampliam as oportunidades e o "potencial de metamorfose" e de autonomia pre- 
sentes nestas comunidades. Os representantes e líderes locais atuam como agentes de transformação, indicando "caminhos" e alternativas, procurando transformar não só traj etórias individuais, mas projetos que beneficiem as comunidades de maneira geral, reforçando o chamado capital social e as organizações sociais presentes. Projetos, entendidos aqui como a capacidade dos indivíduos de planejar o seu futuro e, com isso, contribuir para dar sentido à sua experiência fragmentada (Kuschnir, 2001).

Os representantes locais desempenham através do processo de mediação cultural papelchave no processo de socialização, objetivando ampliar oportunidades, transmitir valores, construir identidades, transformar trajetórias e projetos diante da situação de risco e vulnerabilidade social. Afinal, a imagem de crianças e jovens sem oportunidades e expectativas, sendo inseridas no tráfico de drogas como possibilidade de ganho imediato é uma realidade em $M$ anguinhos e nas demais favelas da cidade.

Devemos ressaltar que esse papel de mediador não ocorre de forma harmoniosa ou passiva. 0 mediador é mais do que um simples intermediário entre "mundos" estáticos. Afinal, 0 sucesso do mediador depende de estratégias que visem ampliar as suas esferas de relações e redes de contato. Na mediação estão presentes diversos interesses, que, dependendo do sucesso ou fracasso dos projetos, dão prestígio, honra e credibilidade social ao papel de liderança. $\mathrm{N}$ a realidade, são esses contatos, trânsitos, acessos e informações - de políticos, instituições, organizações sociais, amigos entre outros - que constituem ferramentas fundamentais de suas atuações, constituindo ao mesmo tempo decorrências e produtores da sua inserção social privilegiada.

\section{Significados e representações nas estratégias de ação}

O desempenho das lideranças comunitárias como mediadores culturais está associado às representações e às categorias de pensamento e classificação que possuem a respeito do que eles denominam "lazer, esporte e cultura". É por intermédio dessas categorias - que organizam as estruturas de pensamento - que podemos compreender o "ponto de vista" dessas lideranças e, portanto, dos nossos informantes. I mporta considerar quais são as "molduras" que, de certa forma, explicam as estratégias de atuação dos representantes locais (D urkheim $\&$ M auss, 2001). Assim, interessa saber quais são os sentidos e os significados que os representantes de $M$ anguinhos dão às iniciativas no campo do "lazer, esporte e cultura"? E ainda, quais são as categorias associadas a elas?

Como dissemos, foi possível identificar que todos os informantes, com apenas uma única exceção, consideram as políticas e as iniciativas nessas áreas fundamentais p para a região. Afinal, dos 18 informantes consultados, 11 pelo menos declararam que desenvolviam ou já desenvolveram al guma iniciativa nas áreas de lazer, cultura e esporte. Inclusive a participação nessas áreas constitui um elemento fundamental para a constituição do papel de liderança comunitária. Como assinala $\mathrm{M}$ arcos Alvito a respeito dos líderes comunitários em Acari: E como chegam a tornar-se líderes comunitários? Ao compararmos os líderes comunitários, enfatizamos as diferenças existentes entre eles. Há, entretanto, um elemento comum a quase todos eles. Com exceção de um, justamente o evangélico, todos os outros participam ou já participaram de atividades que eles chamam de "lazer": futebol, caipira, samba, forró. De fato, foi nessas atividades que eles se constituíram como figuras centrais de relações diádicas (isto é, face a face, diretas, entre dois indivíduos) (2001).

Os líderes comunitários de Manguinhos consideram as iniciativas culturais, de lazer e esporte essenciais, tendo em vista a capacidade de tais ações em se contrapor à violência, especialmente, para os segmentos mais vulneráveis - as crianças e os jovens. Entre a maioria dos informantes, tal perspectiva - na qual a criança e o jovem figuram como foco principal - norteia as representações e os val ores atribuídos à cultura, ao esporte e ao lazer, sendo estes freqüentemente relacionados à educação e à ocupação do tempo "livre". De fato, a ocupação dos morros e das favelas pelo tráfico de drogas a partir da década de 1970, e o conseqüente uso da violência (física e simbólica) como força hierárquica local, tem papel central na configuração das relações e das representações sociais a respeito das favelas cariocas, bem como da cidade como um todo. Afinal, como alerta Alessandra Rinaldi, o medo e a tensão em torno da favela chegou a tal ponto que se elaborou uma percepção determinista na qual o favelado, se não for um criminoso, está na iminência de sêlo (1998).

A imagem de jovens vivendo em favelas, com educação precária e sem ofício específico, 
passa a ser diretamente relacionada ao tráfico de drogas e à criminalidade. Lazer, esporte e cultura agregam - em maior ou menor grau sentidos e significados que não correspondem às fronteiras que "habitualmente" delimitam tais campos. Configuram alternativas que ampliam e modificam o "campo de possibilidades", uma vez que se opõem à violência e à criminalidade. Reúnem uma variedade de valores e éticas que transitam em uma série de planos culturais. Traduzem, assim, a capacidade de modificar a trajetória de crianças e jovens, permitindo um futuro diferente. Como assinalou um dos informantes, permite ser "um parceiro da educação" ou "ocupar o tempo vago das nossas crianças" (Peres, 2004).

Vê-se, portanto, que o problema dos jovens permeia grande parte das preocupações dos principais representantes das comunidades de $M$ anguinhos. Aqui é bom salientar que jovens e crianças são vistos como esperança e futuro em quase todas as sociedades e estratos sociais. Assim, os principais representantes da vida associativa de M anguinhos, sem dúvida, expressam a preocupação com um futuro cheio de incertezas e riscos, cujo antídoto está, em grande parte, constituído de atividades e projetos que envolvem cooperação, diálogo, confiança mútua, enfim, valores ligados ao fortalecimento da cidadania e do capital social.

Deve-se destacar, neste sentido, que o problema central se circunscreve ao tempo qualificado como ocioso. É "o não ter o que fazer" que se constitui em tempo-arriscado ou tempo-problema. Contudo, o importante é que esta perspectiva se configura numa equação que conjuga a falta de oportunidades, ou seja, "não ter o que fazer", às condições de pobreza e exclusão social com todas as suas variáveis, resultando no risco da inserção de crianças e jovens na criminalidade. Cultura, lazer e esporte são vistos, sobretudo, como meio e não como fim em si mesmo, tal como a literatura tem apontado (Park, 1979; Elias \& Dunning, 1992; Zaluar, 2003, 1998). E é justamente a partir desta percepção "midiática" que as atividades culturais se revestem de uma capacidade socializadora e transformadora. Afinal, o objetivo é "prender o tempo da criança ali", sen do "um chamarisco [...] para jogar para outras atividades", procurando abrir a mente dessas crianças e elas passarem a ver que existe um outro mundo aí fora ... que não existe só aquele mundinho [...] de comunidade [...], como salientou um dos informantes (Peres, 2004).

Neste sentido, a importância das iniciativas no campo do lazer, esporte e cultura em M anguinhose, em áreas faveladas da cidade, está relacionada à aquisição de valores morais capazes de modificar a percepção de crianças e jovens sobre a "vida", afastando-os da violência e do mundo do crime. É através de atividades lúdicas e de "bate-papos" informais que valores são incorporados, ajudando a delinear a índole e o caráter dos jovens e crianças. Em outras palavras, é a partir da relação entre lazer, cultura e esporte, com sinal positivo de um lado, e violência e criminalidade associados à ociosidade com sinal negativo do outro, que representantes locais atuam como mediadores culturais e agentes transformadores. U m sistema classificatório simples, que pauta e possibilita as iniciativas dos representantes locais, pode ser visualizado no quadro 1.

\section{Quadro 1}

Categorias de atuação dos representantes comunitários.

\begin{tabular}{ll}
\hline Positivo ( + ) & Negativo ( - ) \\
\hline Lazer, cultura e esporte & Violência e criminalidade \\
Educação, saúde e qualidade de vida & Ociosidade \\
Diversidade de opções & Ausência de opções \\
Disciplina, regras, normas e valores & Desordem/D egeneração/Vício \\
Mudança/Transformação & Passividade/Acomodação \\
Família & Segregação/Quadrilha \\
Sociabilidade/Cidadania & Ruptura/Anomia \\
Vontade & Desleixo/Passividade/“Vida fácil” \\
Futuro & Presente \\
Movimento & Inércia \\
M eio/“Chamarisco” & Destino/Fim
\end{tabular}

Fonte: Peres (2004). 
As categorias de pensamento e o esquema simbólico daí derivado - embora flexíveis, já que existem fluxos e continuidades - expressam e são pautados por oposições "fundamentais" entre valores. Afinal, a tensão entre os dois pólos fundamenta a organização e significação do "mundo".

Entretanto, embora seja atribuído ao esporte, lazer e cultura um papel fundamental na redução da violência e no afastamento de crianças e jovens do tráfico e do crime em geral, há, ao que parece, uma relação ambígua, presente no próprio imaginário da população, já que as atividades do tráfico de certa forma também propiciam e subsidiam possibilidades de lazer no interior das comunidades. 0 tráfico, ao mesmo tempo em que cria condições e promove oportunidades de lazer, também as restringe, em vista do ambiente violento que impõe limites para a vivência destes momentos. Contradições, conflitos e tensões estão permanentemente presentes no dia-a-dia de M anguinhos eno papel das lideranças comunitárias como mediadores culturais.

\section{D esafios para uma agenda no campo da "cultura, lazer e esporte"}

0 contexto de violência na qual o tráfico vem se tornando a representação central de poder nas favelas altera as redes de reciprocidade e solidariedade ou ainda o sistema de valores compartilhados entre moradores de tais comunidades (Zaluar, 1997). Em alguns casos, o poder e autoridade do tráfico são de tamanha magnitude que interferem não apenas em momentos críticos, quando a polícia ou outro grupo "entra em guerra" com o tráfico, mas no dia-a-dia dos moradores de favelas. Tais modificações nos laços e nas redes de solidariedade e sociabilidade, e até mesmo no campo dos valores, não ficam restritas às favelas, mas estende-se a toda a sociedade. A conjunção entre o crescimento, a difusão e o medo da violência aumenta cada vez mais a intolerância em relação ao "outro", inviabilizando contatos e soluções comuns. A violência estimula, sem dúvida, uma nova construção simbólica, através de categorias polarizadas, na qual grupos são classificados como perigosos ou indesejáveis (Caldeira, 2000).

Mudanças no espaço público acabam por restringir a participação cidadã, na medida em que inviabilizam os princípios de acessibilidade e circulação, que são as bases do espaço pú- blico moderno. 0 encontro, a troca e a interação dos "diferentes" e das "diferenças" aparecem assim cada vez mais ameaçados. N este sentido, a violência, ao reordenar de maneira simplista a dimensão simbólica em relação ao "outro", cria sérios desafios à constituição e ao fortalecimento do espaço público e do exercício da democracia.

Por outro lado, pudemos perceber que há uma importante clivagem política entre as associações de moradores, tradicional órgão representativo dos moradores, e outras iniciativas sociais - que se inserem, no que podemos chamar de novos movimentos sociais ou de "novo associativismo". Nestes movimentos, que conquistaram peso político na década de 1990, a lógica organizacional é marcada pela constituição de parcerias variadas (tanto com o setor público quanto o setor privado), do trabalho em rede e em diversos campos de atuação. De acordo com Vieira, este tipo de associação não demanda di retamente o Estado, mas influencia 0 sistema político e econômico ao colocar questões temáticas ao Estado e ao mercado, não ficando, de modo algum, restritas ao mundo societário (2001). São, assim, movimentos de organização da sociedade civil que dependem menos das administrações públicas para a condução de suas iniciativas - que abrangem desde projetos educativo-sociais até denúncias públicas de discriminação e violação dos direitos humanos, visando justamente chamar a atenção pública para tais questões. Buscam, portanto, dar uma maior visibilidade a atores sociais e temáticas antes excluídas do cenário político.

Diferentemente das iniciativas sociais, as associações de moradores têm uma longa trajetória. Desde o início, as associações tiveram sua história vinculada ao poder público e, de certo modo, tentaram pautar suas ações de acordo com o contexto político governamental (Leeds \& Leeds, 1977; Paiva, 2000). As associações de moradores, na perspectiva de Vieira, se configuram como associações [...] que se institucionalizaram em campos predefinidos de ação, burocratizando-se com temas fixos do passado (Vieira, 2001).

Afinal, as relações e as práticas políticas em $M$ anguinhos são delineadas, em maior ou menor grau, por uma diversidade de significados e representações que permeiam o dia-a-dia das lideranças locais. Redes de interações, alianças e contatos políticos são permanentemente desenhados de acordo com o contexto e situação política, bem como pela percepção que os re- 
presentantes comunitários têm de si mesmos e do poder público. 0 cenário composto por práticas diferenciadas, representações discordantes em relação ao poder público e de acusações recíprocas entre as associações de moradores e iniciativas sociais aponta para uma importante clivagem política que, ao mesmo tempo, é fruto e conseqüência tanto do modo de proceder como de suas respectivas visões de mundo, como podemos observar no quadro 2.

Deste modo, uma das hipóteses para a dificuldade na construção de uma agenda comum, apesar da convergência quanto à preocupação com os jovens, seria justamente a disputa pelo poder que opõe líderes tradicionais, representantes das suas respectivas comunidades, e representantes das novas organizações e iniciativas sociais. 0 que está em jogo é a disputa por capital político e simbólico na região. Enquanto as associações buscam manter o monopólio que faz delas a principal representante e interlocutora das demandas comunitárias, as "no- vas" iniciativas sociais colocam tal monopólio em discussão.

Enfim, diferenças nas práticas e nas percepções políticas entre as associações de moradores e as iniciativas sociais acabam por delinear e fomentar clivagens e desconfianças políticas entre esses dois importantes atores sociais da vida comunitária de Manguinhos, dificultando, por sua vez, a construção de estratégias e de uma agenda comum para o desenvolvimento da região e para a implementação de atividades culturais e esportivas de maior al cance social. A natureza de tais conflitos se revela nas posi ções diametralmente opostas entre representantes de associações de moradores e de iniciativas sociais, como podemos ver no quadro 2 (Peres, 2004).

Assim, o cenário de violência conjugado à situação de desconfiança e conflitos presente em $M$ anguinhos nos remete diretamente à discussão sobre capital social. Sucintamente, na literatura consultada, a idéia de capital social se relaciona com a capacidade de se estabel ecerem

Quadro 2

Características, diferenças e divergências entre associações de moradores e iniciativas sociais.

\begin{tabular}{|c|c|c|}
\hline & Associações de moradores & Iniciativas sociais \\
\hline $\begin{array}{l}\text { Percepção a respeito } \\
\text { do circuito político }\end{array}$ & $\begin{array}{l}\text { "É assim que funciona" } \\
\text { "N ão tem como mudar" }\end{array}$ & $\begin{array}{l}\text { "M eio sujo" } \\
\text { "troca de favores" } \\
\text { assistencialista } \\
\text { "Tem que mudar" }\end{array}$ \\
\hline $\begin{array}{l}\text { "Ponto de vista" a respeito } \\
\text { do próprio posicionamento } \\
\text { político }\end{array}$ & Pragmático & “Teórico/Politizado" \\
\hline Direcionamento da ação & Localizado & Abrangente \\
\hline Parâmetros de êxito & Oferecimento/N ecessidade & Conquista/Reivindicação \\
\hline $\begin{array}{l}\text { Percepção a respeito } \\
\text { dos moradores }\end{array}$ & Dependentes/Carentes & Sujeitos de direito \\
\hline Processo de mudança & Imediata & Prolongada \\
\hline Meio de transformação & $\begin{array}{l}\text { M udança "Concreta" } \\
\text { Soluções Pontuais }\end{array}$ & "Conscientização" \\
\hline \multirow[t]{4}{*}{$\begin{array}{l}\text { Conflitos, oposições } \\
\text { e divergências atribuídas }\end{array}$} & $\begin{array}{l}\text { Predomínio de interesses } \\
\text { pessoais }\end{array}$ & $\begin{array}{l}\text { Ação em benefício } \\
\text { da própria entidade/ } \\
\text { Falta de transparência }\end{array}$ \\
\hline & Assi stencialistas/“política velha” & “Românticos/ideológicos” \\
\hline & Envolvimento com o tráfico & Controle de informações \\
\hline & $\begin{array}{l}\text { Impedem a participação } \\
\text { comunitária }\end{array}$ & $\mathrm{N}$ ão representam a comunidade \\
\hline
\end{tabular}

Fonte: Peres (2004). 
laços e redes de confiança e cooperação a fim de produzir e construir bens e conquistas coletivas. Trata-se, portanto, do envolvimento com a "coisa pública", cujas conquistas se traduzem em benefícios comuns (Putnam, 1996; Araujo, 2003). Assim, a convergência de interesses somada à integração e participação comunitária teriam um impacto positivo para o desenvolvimento e para o fortalecimento de agendas democráticas e participativas.

\section{Considerações finais}

Lazer carrega diversos significados e interpretações. Entretanto, ao ser tomado como componente da cultura, evidencia não apenas as suas relações com outras esferas sociais, mas possibilita o conhecimento dos significados e valores simbólicos para aqueles que os vivem, bem como aponta a dimensão política que permeia a temática. Foi possível observar práticas e percepções políticas dos líderes comunitários de $M$ anguinhos, configurados em duas lógicas distintas de organização comunitária, a das associações de moradores e das "novas" iniciativas sociais.

0 papel fundamental desempenhado pelos líderes comunitários como mediadores culturais, seja no campo da cultura ou em qualquer outro, pode ser potencializado desde que existam laços de confiança e cooperação, de modo a produzir consenso e fortalecer uma agenda comum. Confiança e cooperação estimulam e intensificam a participação social e a sociabilidade em $M$ anguinhos, ao mesmo tempo em que impulsionam a capacidade organizativa. A pontamos, assim, para a necessidade do fortalecimento e consolidação da cidadania, através da ampliação do acesso e do debate políti$\mathrm{co}$, onde se prioriza a negociação entre diversos atores e a participação popular na definição da agenda e nas diversas instâncias de tomada de decisão. A final, Cidadania, democracia e direitos, mesmo quando confrontados com desigualdade, miséria e exclusão social, revelam o caminho possível da luta política e da busca de autonomia. Não há processo de desenvolvimento de direitos sem compromissos democráticos explícitos em torno da redução da iniqüidade social, o que certamente implica o fortalecimento da sociedade civil e de suas formas plurais de organização, permitindo a emergência de novas identidades e de novas representações em torno da questão social (Bodstein, 1997).
$\mathrm{Na}$ constituição de novos espaços e circuitos de discussão e de decisão é necessário reafirmar e reforçar circuitos de participação e mediação política e cultural. Em outras palavras, é necessário apostar na realização da "mediação dos mediadores" no plano político e cultural. A mediação tanto cultural quanto política, em conjunto com regras de reciprocidade e sistemas de participação cívica, desempenham papel-chave para fortalecer o capital social e para dirimir clivagens que impedem a construção de uma agenda comum.

0 grande desafio, além da criação de laços de confiança e cooperação comunitária, passa pela inversão das relações verticais de poder a partir de uma maior interlocução e co-responsabilização na gestão pública, ampliando os canais participativos para os setores excluídos da população, num processo de democratização da administração pública.

U ma das contribuições desse artigo está no fato de ressaltar o papel das lideranças comunitárias como mediadores e de destacar que lazer, esporte e cultura são assuntos fundamentais na dinâmica comunitária e na implementação de programas sociais e de saúde. A análise apontou justamente para o fato de que iniciativas nas áreas de lazer, cultura e esporte possuem centralidade no fortalecimento da cidadania e de redes de solidariedade. Tais iniciativas, como vimos, possuem um potencial de sociabilidade que amplia o campo de possibilidades, abrindo caminhos e opções, diante das dificuldades do contexto social. Além disso, agregariam, através da mediação cultural, valores simbólicos, reconstituindo identidades e relações que ultrapassam em certo sentido os campos do lazer, do esporte ou da cultura propriamente ditos. Propiciam a reafirmação de valores relacionados ao diálogo, à cooperação, à mobilização, à disciplina, à conscientização, à autoridade, valores fundamentais para uma apropriação crítica e reflexiva em relação ao contexto social em que vivem. Deste modo, atividades culturais e de lazer em sentido amplo, como vimos, merecem figurar na agenda de desenvolvimento social e de promoção da saúde. Como nos lembra Alba Zaluar, políticas públicas em áreas faveladas [...] devem ser implementadas não porque os pobres constituam um perigo permanente à segurança, não porque venham a ser as classes perigosas, mas porque um país democrático ejusto não pode existir sem tais políticas (1997). 


\section{Colaboradores}

FF Peres trabalhou na concepção teórica, desenho metodológico, pesquisa de campo, análise dos dados e elaboração do texto; R Bodstein, na concepção teórica, desenho metodológico, análise dos resultados e elaboração do texto; CL Ramos, na elaboração dos instrumentos de pesquisa e de coleta de dados; eWB M arcondes, na elaboração dos instrumentos de pesquisa e de coleta de dados.

\section{Referências bibliográficas}

Aguileta IL 2000. Cultura y ciudad: manual de política cultural municipal. Ediciones Trea, Gijón.

Alvito M 2001. As cores de Acari: uma favela carioca. Editora FGV, Rio de Janeiro.

Araujo M CD 2003. Capital social. Jorge Zahar Ed., Rio de Janeiro.

Bauman, Z 2003. Comunidade: a busca por segurança no mundo atual. Jorge Zahar Ed., Rio de Janeiro.

Bodstein R, Zancan L, Ramos, CL \& M arcondes, WB 2004. Avaliação da Implantação do Programa de Desenvolvimento Integrado em $M$ anguinhos: impasses na formulação de uma agenda local. Ciência $\&$ Saúde Coletiva 9(3)593-604.

Bodstein R \& Zancan LF 2003. M onitoramento e avaliação do programa de desenvolvimento local integrado e sustentável (DLIS) M anguinhos: relatório de pesquisa. DCS/ENSP/Fiocruz/Finep, Rio de Janeiro.

Bodstein R \& Zancan L 2002. Avaliação das ações de promoção da saúde em contextos de pobreza e vulnerabilidade social, pp. 39-59. In L Zancan, R Bodstein \& WB Marcondes (orgs.). Promoção da saúde como caminho para o desenvolvimento local: a experiência em M anguinhos-RJ. Abrasco-Fiocruz, Rio de Janeiro.

Bodstein R, Zancan L \& Estrada DD 2001. M anguinhos: guia de equipamentos e iniciativas sociais. Fiocruz, Rio de Janeiro.

Bodstein RCA 1997. Cidadania e modernidade: emergência da questão social na agenda pública. Cadernos de Saúde Pública 13(2):185-193.

Brant L 2002. M ercado cultural: panorama crítico com dados e pesquisas e guia prático para gestão e venda de projetos. Escrituras Editora, São Paulo.

Buss PM 2000. Promoção da saúde e qualidade de vida. Ciência \& Saúde Coletiva 5(1):163-177.

Caldeira TPR 2000. Cidade de muros: crime, segregação e cidadania em São Paulo. Ed. 34-Edusp, São Paulo.

Dumazedier J 2001. Lazer e cultura popular. Editora Perspectiva, São Paulo.

Dumazedier J 1999. Sociologia empírica do lazer. Editora Perspectiva, São Paulo.

Durkheim E \& M auss M 2001. Algumas formas primitivas de classificação, pp. 399-455. In M M auss. Ensaios de sociologia. Editora Perspectiva, São Paulo.

Elias N \& Dunnig E 1992. A busca da excitação. Difel, Lisboa.
Faria H 2003. Políticas públicas de cultura e desenvolvimento humano nas cidades, pp. 35-51. In L Brant (org.). Políticas culturais. vol.1. Editora M anole, São Paulo.

Ferreira JR \& Buss PM 2002. 0 que o desenvolvimento local tem a ver com a promoção da saúde?, pp. 15-37. In L Zancan, R Bodstein \& WB M arcondes (orgs.). Promoção da saúde como caminho para o desenvolvimento local: a experiência em M anguinhos-RJ. Abrasco-Fiocruz, Rio de Janeiro.

Fundação Centro de D efesa dos Direitos Humanos Bento Rubião (FCDDH) 2000. Diagnóstico Rápido Participativo de $M$ anguinhos. Rio de Janeiro.

Geertz C 1989. A interpretação das culturas. LTC - Livros Técnicos Científicos, Rio de Janeiro.

Giddens A 2002. M odernidade e identidade. Jorge Zahar Ed., Rio de Janeiro.

Kliksberg B \& Tomassini L 2000. Capital social y cultura: claves estratégicas para el desarollo. BID/Fondo de Cultura Económica de Argentina, Buenos Aires.

Kuschnir K 2001. Trajetória, projeto e mediação na política, pp. 137-164. In G Velho \& K Kuschnir (orgs.). Me diação, cultura e política. Aeroplano Editora, Rio de Janeiro.

Kuschnir K 2000. 0 cotidiano da política. Jorge Zahar Ed., Rio de Janeiro.

Kuschnir K 1999. Eleições e representação no Rio de Janeiro. Relume-Dumará-UFRJ, Rio deJaneiro.

Leeds A \& Leeds E 1977. A sociologia do Brasil urbano. Jorge Zahar Ed., Rio de Janeiro.

M asi DD 2000. 0 ócio criativo. Sextante, Rio de Janeiro.

M elo VA 2003. Lazer, meio ambiente e envolvimento comunitário, pp. 73-88. In VA M elo (org.). Lazer e minorias sociais. Ibrasa, São Paulo.

M elo VA \& Alves Júnior ED 2003. Introdução ao lazer. Editora $\mathrm{M}$ anole, São Paulo.

Paiva M AP 2000. Espaço público e representação política. EdUFF, Niterói.

Park RE 1979. A cidade: sugestões para a investigação do comportamento humano no meio urbano, pp. 26-67. In $O$ Velho (org.). 0 fenômeno urbano. Jorge Zahar Ed., Rio de Janeiro.

Pawson R 2003. N othing as Practical as a Good Theory. Evaluation 9(4):471-490.

Peres FF 2004. Lazer e cultura na agenda local: mobilização 
e ação coletiva em M anguinhos. Dissertação de mestrado. Escola Nacional de Saúde Pública, Fiocruz, Rio deJaneiro.

Potvin L, Haddad S \& Frohlich L 2001. Beyond process and outcomes evaluation: a comprehensive approach for evaluating health programs, pp. 45-62. In IG Rootman, B Hyndman, DV M acQueen, L Potvin, J Springett \& E Ziglio (eds). Evaluation in health promotion: principles and perspectives. World $\mathrm{H}$ ealth Organization, Copenhagen.

Putnam RD 2000. Bowling alone: the collapse and the revival of american democracy. Simon and Schuster, Nova York.

Putnam RD 1996. Comunidade e democracia: a experiência da Itália moderna. Editora FGV, Rio de Janeiro.

Rinaldi AA 1998. Marginais, delinqüentes e vítimas: um estudo sobrea representação da categoria favelado no tribunal do júri da cidade do Rio de Janeiro, pp. 299322. In A Zaluar \& M Alvito (orgs.). U m século de favela. Editora FGV, Rio de Janeiro.

Rootman IG, Hyndman B, MacQueen DV, Potvin L, Springett J \& Ziglio E 2001. Evaluation in health promotion: principles and perspectives. World Health Organization, Copenhagen.

Simmel G 1979. A metrópole e a vida mental, pp. 11-25. In 0 Velho (org.). 0 fenômeno urbano. Jorge Zahar Ed., Rio de Janeiro.
Sullivan H, Barnes M \& M atka E 2002. Building colaborative capacity trough "theories of change". Early lessons from the evaluation of $\mathrm{H}$ ealth Action Zones in England. Evaluation 8(2):205-226.

Velho G 1999a. Projeto e metamorfose: antropologia das sociedades complexas. Jorge Zahar Ed., Rio de Janeiro.

Velho G 1999b. Individualismo e cultura: notas para uma antropologia da sociedade contemporânea. Jorge Zahar Ed., Rio de Janeiro.

Velho G 2001. Biografia, trajetória e mediação, pp. 13-28. In G Velho \& K Kuschnir (orgs.). M ediação, cultura e política. Aeroplano Editora, Rio de Janeiro.

Vieira L 2001. Os argonautas da cidadania: a sociedade civil na globalização. Record, Rio de Janeiro.

Vieira L \& Bredariol C 1998. Cidadania e política ambiental. Record, Rio de Janeiro.

Zaluar A 2003. Gangues, galeras e quadrilhas: globalização, juventude e violência, pp. 17-57. In H Vianna (org.). Galeras cariocas: territórios de conflitos e encontros culturais. Editora UFRJ, Rio de Janeiro.

Zaluar A \& Alvito M 1998. Introdução, pp. 7-24. In A Zaluar \& M Alvito (orgs.). U m século de favela. Editora FGV, Rio de Janeiro.

Zaluar A 1997. Exclusão e políticas pública: dilemas teóricos e alternativas políticas. Revista de Ciências Sociais 12(35):29-47.

Artigo apresentado em 10/10/2004

Aprovado em 25/01/2005

Versão final apresentada em 11/01/2005 